\title{
CONTO MARAVILHOSO, FÁBULA E AQUARELA: A OBRA DE BEATRIX POTTER E A DIVERSIDADE NO OLHAR PARA A LITERATURA INFANTIL
}

\author{
Gabriela Regina Soncini \\ Mestranda em Letras pela Universidade Federal de Uberlândia (UFU) \\ gaby.soncini@hotmail.com
}

\section{RESUMO}

Este artigo discute aspectos narrativos da fábula e do conto maravilhoso na obra da escritora e ilustradora inglesa Beatrix Potter, no que concerne aos elementos diversos que os livros da autora e ilustradora representam, realizando um movimento de toque no Reino Encantado, conforme o enfoque teórico de J. R. R. Tolkien (2013). O encontro de estruturas narrativas característico dos escritos de Potter verifica-se igualmente no toque sutil das aquarelas que os ilustram e na preocupação com o formato dos livros para crianças. A diversidade de formas narrativas observada por Peter Hunt (2010) nos textos destinados à criança salienta a relevância da contribuição de Potter para o campo da literatura infantil.

Palavras-chave: Literatura infantil, fábula, contos de fadas, ilustração, Beatrix Potter.

\section{ABSTRACT}

This article discusses narrative aspects of the fable and the wonderful tale in the work of the English writer and illustrator Beatrix Potter, regarding the diverse elements that the author and illustrator's books represent, performing a touch movement in the Enchanted Kingdom, according to the theoretical approach of J.R.R. Tolkien (2013). The encounter of narrative structures characteristic of Potter's writings also occurs in the subtle touch of the watercolors that illustrate them and in the preoccupation with the format of books for children. The diversity of narrative forms observed by Peter Hunt (2010) in children's texts highlights the relevance of Potter's contribution to the field of children's literature.

Keywords: Children's literature, fable, fairy tale, illustration, Beatrix Potter. 


\section{Introdução}

Beatrix Potter foi uma autora e ilustradora inglesa nascida em 28 de julho de 1866. Devido a uma infância solitária, a escritora começou a estudar sozinha história natural e artes, iniciando assim suas primeiras ilustrações nas áreas de botânica e zoologia. Embora pertencesse a uma família burguesa, a cidade e os requintes da vida em sociedade não agradavam a menina. Adulta e já escritora reconhecida, Potter passaria a residir no campo, buscando inspiração junto à natureza.

O mais famoso entre os livros de Potter é sua primeira publicação: $A$ história do Pedro Coelho. Escrita para um dos filhos da última ama da escritora, a história foi realizada em forma de cartas, com diversas ilustrações para entreter a criança, mas apenas em 1902 que The Tale of Peter Rabbit foi publicado em forma de livro.

Quando faleceu, em 1943, a escritora deixou toda a propriedade que possuía para a Nacional Trust, organização protetora do meio ambiente, como forma de preservação daquelas terras. Potter prezava muito a natureza, tendo manifestado esse sentimento em toda a sua obra. Além dos livros escritos pela autora, ao longo do tempo foram lançados filmes e séries sobre a escritora e suas histórias.

The World of Peter Rabbit and Friends, no Brasil com o título de Peter Rabbit e seus amigos, foi uma série produzida pela BBC do Reino Unido entre 1992 e 1995. A TV Cultura exibiu a série no Brasil, a partir de 1993, com os nove episódios dublados; a produção foi bastante fiel às aquarelas delicadas e sutis de Potter. Todos os episódios dessa série iniciavam-se com a escritora pintando uma aquarela no campo, ao lado de seu cachorro. A paisagem vai se abrindo gradualmente e outros animais em seus meios 
naturais vão sendo mostrados, dando início a uma chuva torrencial que faz com que a escritora guarde seus materiais, retornando para sua casa juntamente com o seu animal.

Ao chegar a seu lar, ela se encontra com o seu coelhinho Peter que espera, em meio aos papéis de carta, por uma nova história. A escritora prepara uma xícara de chá e começa a escrever uma narrativa em forma de carta para as crianças do vilarejo, enquanto a chuva continua a cair. Dessa forma, como se Beatrix Potter estivesse narrando sua própria história sendo escrita, uma animação se inicia. Cada episódio conta a história de um dos livros da escritora e, apesar de ter sido exibida pela TV Cultura, a série é desconhecida pelo grande público, até mesmo entre outros programas, séries e animações para crianças de grande sucesso exibidas pela emissora na década de 90 do século passado.

Em 2006, os estúdios Imagens Filmes produziram o filme Miss Potter que conta um pouco da história da autora, desde sua infância até o processo de edição de seus livros. O filme também preserva a sutileza das aquarelas de Potter e o clima bucólico. A produção cinematográfica trabalha de forma delicada a representação de Potter como uma mulher à frente do seu tempo, afinal a escritora teve coragem de buscar um mercado editorial com pouco espaço para mulheres que escreviam e ilustravam livros, um mercado editorial com pouco espaço para "coelhos de paletó", como ironiza um editor em uma cena do filme em questão. O filme foi protagonizado pela atriz Renée Zellweger no papel de Beatrix Potter e é um interessante e bonito material para conhecermos um pouco da escritora e de todo o seu processo de criação.

Seus livros ainda são pouco conhecidos no Brasil. A História de Pedro Coelho foi publicada pela editora Lótus do Saber em 2009 e, a partir de 2014, a Companhia das Letrinhas começou a editar outras narrativas de Potter. A coletânea As Aventuras de 
Pedro Coelho reúne quatro histórias: "A história do Pedro Coelho", "A História do coelhinho Benjamin", "A História dos coelhinhos felpudos" e "A História do Sr. Raposão". Tanto a edição da Lótus do Saber como a da Companhia das Letrinhas trazem as aquarelas originais da autora. Ainda em 2014, a Companhia das Letrinhas publicou Pedro Carteiro, inspirado nas histórias originais de Potter. A obra em questão segue os moldes de O Carteiro Chegou (2010), escrito e ilustrado por Janet e Allan Ahlberg - as cartas que se encontram em ambas as obras tornam os livros interativos para as crianças.

Convém citar o recente Pedro Coelho, produzido em 2018 pela Sony Pictures Animation. O filme aborda a obra da autora de forma mais atual, porém ao unir técnicas de animação 3D com atores reais, distancia-se um pouco da sutileza das aquarelas de Potter. A produção tem pontos positivos e outros tratados com certa superficialidade, mas sua realização, nesses mais de 100 anos da publicação de $A$ História de Pedro Coelho, é interessante como forma de apresentar a escritora para uma nova geração e despertar, assim, o interesse das crianças por seus livros ilustrados em aquarela.

Além de refletir sobre a importância de Beatrix Potter como escritora e ilustradora de livros infantis, esse artigo pretende discutir um dos aspectos fundamentais de sua obra: a miscelânea de características de contos maravilhosos e de fábulas tradicionais, inscrita em uma proposta autêntica e inovadora, relativa ao formato material, à recepção do público leitor e às ilustrações em aquarela que acompanham a história. O objetivo é mostrar que as narrativas de Potter incluem certa diversidade de elementos em sua estrutura, reunindo em uma única obra propostas de contos de fadas, fábulas e literatura infantil moderna. Por conseguinte, esse trabalho pretende contribuir para uma reflexão acerca da obra da escritora, assim como da literatura infantil na pesquisa acadêmica. 


\section{Entre a fábula e o conto maravilhoso}

A literatura infantil é ampla, fluida e plural; estudá-la exige uma poética singular, segundo Peter Hunt (2010). O estudioso afirma que a literatura infantil é gênero que abarca quase todos os outros gêneros literários; sendo assim, é difícil definir "uma literatura infantil", pois a mesma envolve elementos textuais diversos e imagéticos para a criança leitora.

Em Crítica, teoria e literatura infantil, Hunt nos ensina que os "textos para a criança" (nomenclatura muito utilizada e defendida pelo autor), podem ser estudados de diversos pontos de vista, como o histórico, contemporâneo, literário, artístico, ou seja, estudar a literatura infantil e pesquisá-la é atentar para a sua diversidade, uma única definição de literatura infantil não a compreende como um todo. Outro aspecto da literatura infantil é a sua correlação com o conceito de infância: "A infância não é hoje (se é que alguma vez foi) um conceito estável. Por conseguinte, não se pode esperar que a literatura definida por ela seja estável" (HUNT, 2010, p. 94).

Porém, apesar de seu aspecto movente, a literatura infantil também compreende os contos de fadas, textos que possuem certa unicidade de temas e trajetos presentes em suas construções narrativas, conforme observa Nádia Batella Gotlib (1991), em A Teoria do Conto. As narrativas clássicas permanecem através dos tempos, embora tenham variações e pluralidades, seus temas são únicos e atemporais; desse modo, as crianças de hoje continuam apreciando os originais e suas variadas adaptações e versões, conhecem os personagens clássicos e os reconhecem em diversas situações, segundo Gotlib (1991), os contos se renovam sem se desmancharem. 
Quando falamos de contos maravilhosos ou contos de fadas, já os diferenciamos das chamadas fábulas, que são consideradas outro tipo de narrativas; muitas fábulas conhecidas não têm o caminho narrativo de um conto de fadas; normalmente elas apresentam um caminho mais breve, seja em extensão material escrita, na questão espacial propriamente, como temporalmente ao contar uma situação mais curta e situada, com o objetivo de avaliar, ensinar ou criticar atitudes humanas.

A frase que inicia a obra mais conhecida de Potter, A História de Pedro Coelho, exemplifica o emprego da fórmula inicial do conto de fadas: "Era uma vez quatro coelhinhos que se chamavam Flópsi, Mópsi, Rabinho-de-Algodão e Pedro. Eles moravam com a mamãe num banco de areia, bem embaixo de uma árvore grandona" (POTTER, 2009, p. 9, grifo nosso). Temos, logo que abrimos o livro, a tão conhecida expressão "Era uma vez"; essas palavras que tornam o tempo da história outro. "Era uma vez" quer dizer que a singularidade do momento da narração unifica o passado mítico - fora do tempo com o presente único - no tempo - daquela pessoa que a escuta e a presentifica" (MACHADO, 2004, p. 23). Ao ler ou escutar o "Era uma vez", já sabemos a priori que vamos nos deparar com um conto de fadas, porém o livro de Potter vai apresentando elementos da fábula, tais como: animais antropormóficos, uma atitude desobediente sendo de certa forma castigada e uma moral bem presente no desfecho da história.

Pedro Coelho é o filho desobediente que não escuta os conselhos da mãe para não entrar na horta do Seu Gregório, mas por curiosidade e por ser muito guloso, vai mesmo assim e se mete em uma série de confusões e em uma sucessão de apuros para conseguir sair do lugar. No entanto, a moral do final do livro de Beatrix Potter difere da moral de algumas fábulas conhecidas: 
É com muita pena que eu tenho de contar que à noite o Pedro não se sentiu muito bem. A mamãe pôs o Pedro na cama, fez chá de camomila e deu para ele beber. "Tomar uma colher de sopa bem cheia na hora de dormir". Mas Flópsi, Mópsi e Rabinho-de-Algodão jantaram pão com amoras e leite bem quentinho (POTTER, 2009, p. 57).

Vemos que Pedro ficou doente pelas suas estripulias, mas foi tratado com o carinho de mãe, e não duramente castigado. A horta do Seu Gregório representa um atrativo para os coelhinhos, mas um perigo por pertencer a um ser humano, que parece se utilizar da horta mais como artifício de armadilha para atrair coelhos do que pelo cuidado em si de plantar. Percebemos que existe uma moral, um ensinamento a ser dado para as crianças, que entre muitas formas, pode ser interpretado como sugestão para não se confiar em tudo o que aparenta ser "bom". Os irmãos de Pedro que se comportaram comeram as gostosuras, portanto, encontra-se presente nas narrativas de Potter o jogo de comportamentos das fábulas. Em seu ensaio "Sobre contos de fadas", Tolkien sugere qual gênero estaria mais próximo das narrativas da escritora:

As histórias de Beatrix Potter situam-se perto da fronteira do Reino Encantado, mas quase sempre fora dele, penso eu. Sua proximidade deve-se em grande parte a seu forte elemento moral - com isso quero dizer sua moralidade inerente, não alguma signaficatio alegórico. Mas Peter Rabbit, apesar de conter uma proibição, e apesar de existirem proibições na terra das fadas (como provavelmente existem em todo o universo, em todos os planos e em todas as dimensões), continua sendo uma fábula de animais (TOLKIEN, 2013, p. 16).

É interessante ressaltar essa "fronteira", pois é onde as histórias de Potter se encontram. No amplo universo da escritora, todas as histórias e personagens se ligam entre os lugares criados por ela mesma. Na edição da Companhia das Letrinhas para As Aventuras de Pedro Coelho existe um mapa de todas as casas, lugares e espaços onde 
vivem os personagens, habitando espacialmente lugares próximos e semelhantes. Concordando com Tolkien, as narrativas de Potter poder ser consideradas fábulas de animais, porém há uma elaboração de universo e outras forças narrativas em conjunto. Segundo Oliveira (2011, p. 20),

a fábula não seria apenas um gênero, uma espécie de narrativa, mas uma qualidade da narrativa, podendo estar presente em qualquer tipo de narrativa, nos contos de fadas, nos contos de aventura, nos mitos, nas lendas, e nas próprias fábulas tomadas em seu sentido restrito.

Diante desse excerto, podemos inferir que as narrativas da escritora vão além para serem nomeadas apenas de fábulas no que concerne apenas em sua estrutura. Há na obra de Potter os elementos essenciais da fábula, como também do conto maravilhoso, seja na figura das personagens, nos atos para vencer obstáculos, nos aprendizados, na aura encantada que povoa o lugar ou na presença do elemento humano nas narrativas. Segundo Tolkien (2013), o conto de fadas é aquele que "toca" o Reino Encantado, mesmo dando a impressão de estar fora desse legítimo conto de fadas considerado pelo teórico, a escritora faz o movimento dentro dele.

Segundo Calvino (1996, p. 108), “o conto de fadas, produção narrativa arcaica do mundo agrícola, representa uma integração do homem no ciclo de reprodução de uma riqueza, sobretudo vegetal e animal". Essas são características marcantes nos livros de Potter, elas se situam em um marco temporal que não se mostra totalmente nas descrições de suas narrativas, sem linearidade ou cronologia exata, valorizando elementos bucólicos, um modo arcaico e natural de ver a vida, a simplicidade do campo, de cuidado e amizade, e da utilização de personagens animais com características 
humanas, seja de forma externa, como na vestimenta e na postura, assim como nas estruturas externas de pensamento.

Com base nas reflexões feitas até aqui, concluímos, tal como Hunt (2010), que a literatura infantil é ampla e abarca diversos gêneros, até mesmo em uma única obra. Nas histórias de Potter visualizamos essa multiplicidade de características que se manifesta no caminho entre a fábula e o conto maravilhoso. Tal pluralidade abrange a aspectos de sua época, de novos pensamentos para a literatura infantil moderna, bem como o desejo expresso da autora por uma vida campestre e a vontade de sempre preservar um vestígio de criança dentro de si mesma. Agora passaremos a analisar o formato e as ilustrações dos livros de Potter, que são uma obra de arte a parte, algo importante para se ler na completude de sua obra.

\section{Mãos pequenas e livros ilustrados}

Um dos aspectos a serem analisados para o estudo e pesquisa das obras de Beatrix Potter, é o diálogo entre a escrita e as ilustrações, a escritora muitas vezes desenhava antes de propriamente escrever suas histórias, e a técnica presente em suas obras é a aquarela, tinta usada diluída em água que traz um movimento de fluidez e delicadeza para os desenhos. Podemos pensar que as ilustrações nas obras de Potter suplementam as histórias, não apenas como extensão do escrito, o que também realizam, mas oferecem uma percepção para além das descrições das palavras.

Em Para ler o livro ilustrado (2011), somos apresentados a uma variedade de formas de livros ilustrados que, de acordo com Sophie Van Der Linden, constituem efetivamente uma forma especifica de expressão, os livros ilustrados podem ser 
pensados de acordo com a criança e o adulto que lê as histórias para as crianças, portanto, muitas vezes o livro ilustrado é voltado para um destinatário duplo.

Potter pensou seus livros para mãos pequenas de criança. Ao serem publicados pela editora Frederick Warne \& Co, seus livros eram editados em formato menor, e foram seguindo um padrão de publicação nesse mesmo modelo. A editora portuguesa Verbo Editorial ao publicar os livros da autora, manteve o mesmo formato que os primeiros originais. No Brasil esse também foi o movimento da editora Lótus do Saber ao publicar em 2009 A História de Pedro Coelho. De acordo com Linden (2011, p. 8-9):

Ler um livro ilustrado é também apreciar o uso de um formato, de enquadramentos, da relação entre as capas e guardas com seu conteúdo, é também associar representações, optar por uma ordem de leitura no espaço da página, afinar a poesia do texto com a poesia da imagem, apreciar os silêncios de uma em relação à outra.

Os livros de Potter foram pensados pela própria autora para se relacionarem com as crianças, fáceis de serem manuseados por elas, com páginas intercaladas de escrita e ilustração. Segundo Hunt (2010, p. 107), "se a literatura é uma experiência total, não podemos ignorar o aspecto de sua materialidade", a estética do livro físico e o espaço no qual a criança o lê, gera uma espécie de relação entre a criança e o livro, a escritora atentou de forma criteriosa para esses detalhes em sua obra. Ainda segundo Hunt (2010), o livro ilustrado pode orquestrar o movimento dos olhos. Feito em tamanho pequeno para mãos de criança, o livro ilustrado de Potter pede uma leitura visual minuciosa, atenta aos pequenos detalhes que a narrativa e as ilustrações apresentam. No livro Era uma vez uma capa (2008), Alan Powers nos indica uma história da literatura infantil através das capas dos livros. Sobre os livros de Potter o autor salienta: 
Potter continuou com suas séries ilustradas em formato pequeno até 1913, e as aquarelas e o traço fino à tinta desafiaram a capacidade de impressão da época. A encadernação normalmente consistia na colagem das aquarelas no centro da capa, que era então forrada com papel colorido, porém sem estampa. Isso causava a sensação levemente arcaica dos chapbook, que combinava com o conteúdo dos livros. Uma sobrecapa e papel acetado com o título da obra protegia os volumes, e raridade de sua sobrevivência Ihes confere um valor que ultrapassa em muito qualquer interesse próprio que eles possam ter (POWERS, 2008, p. 26).

Na recente edição da Companhia das Letrinhas, de 2014, o livro apresenta uma coletânea de histórias e, diferente das edições diminutas, foi editado em formato maior, com mais de uma ilustração por página. Já não é mais para as mãos diminutas pensadas por Potter, apesar de apresentar suas histórias e ilustrações, o livro parece se atentar mais ao adulto que vai ler essas histórias para as crianças. Outro formato material, ou seja, um livro de formato maior proporciona uma experiência diferente de imersão na leitura pela criança:

Acredito que o mais importante na literatura infantil seja a interação singular de um texto com a criança singular em uma situação singular: esta é sempre diferente, sempre complexa e sempre produz um conhecimento que não pode ser generalizado (HUNT, 2010, p. 270).

É essencial compreender toda a singularidade que envolve analisar um livro infantil, desde sua pluralidade de direções, imagens, formatos, até a forma como a criança irá recebê-lo. Portanto, analisar a literatura infantil é caminhar por uma diversidade de trajetos que muitas vezes não serão seguros e estáveis, e sim moventes.

Em O livro por vir, Maurice Blanchot (1984, p. 248) ensina através dos escritos de Mallarmé que o homem é um ser de horizonte, que o espaço do livro "cintila em puro 
fulgor estelar" e ainda "pressupõe um espaço de várias dimensões que só pode ser entendido de acordo com essa profundidade espacial que é necessário apreender simultaneamente a diferentes níveis". Dessa forma, salientamos que toda essa preocupação com a materialidade do livro se abriga na escrita, na proposta que o livro terá e nos diálogos que ele traz dentro de si. Os livros destinados à criança precisam pensar essa proposta espacial de acordo não somente com um objetivo de mercado, mas com a leitura da criança na história, que imersão é essa que se pretende, e que profundas significações vão se abrir nessa relação entre livro e criança. E atentando sempre que dentro de um livro há muitos caminhos e dimensões espaciais.

\section{Considerações finais}

Este artigo teve a intenção de iniciar um olhar sobre os livros de Beatrix Potter, cuja obra oferece amplo campo de pesquisa, já que a autora criou um universo vasto de histórias e aquarelas produzindo uma obra de importância, não somente no cenário da literatura infantil inglesa, como também por todo o mundo. Apresentando aquarelas, elementos textuais e narrativos diversos, os escritos de Potter nos permitem pensar tanto sobre a escritora e o lugar que ocupa dentro da literatura, e sobre os caminhos de análise da literatura infantil, já que a mesma representa diversos gêneros, diversas técnicas ilustrativas e diversas estruturas textuais.

Hunt (2010, p. 49) pontua que os livros destinados à criança ultrapassam a fronteira erudita e popular, abarcando uma grande forma de produção de entretenimento: "Supor que a literatura infantil seja de algum modo homogênea é subestimar sua diversidade e vitalidade". Em uma única obra encontramos muitos 
lugares, como nas histórias que Potter teceu entre a fábula e o conto de fadas, visualizando uma proposta para além das duas formas narrativas tão conhecidas e tradicionais para a criança.

Olhar para a obra de Potter é ter em mente que iremos encontrar em seus livros uma diversidade dentro de um artefato diminuto. Nas suas narrativas encontraremos o toque de reino encantado, a aura maravilhosa dos contos de fadas, o caminho da jornada do herói, a moral oriunda das fábulas, além do trabalho artístico por meio de ilustrações que a compõem e concedem visualmente uma abertura para as narrativas, fazendo de Potter uma interessante autora para se pensar a literatura infantil.

Os personagens criados em seu universo se conhecem, vivem em um mesmo espaço bucólico desenhado pela autora. Quando entrar em contato com sua obra, a criança estará diante desse outro espaço que um conjunto de livros pequeninos guarda:

Ao final de seu panorama, a visão do livro infantil desemboca em um rochedo coberto de flores, bem ao estilo Biederneier. Apoiado em uma deusa azul-celeste, o poeta repousa ali com as mãos melodiosas. Ao seu lado, uma criança alada registra aquilo que a musa lhe inspira. Dispersos ao redor, uma harpa e um alaúde. No seio da montanha anões tocam flauta e violino. No céu, porém, o sol se põe. Assim pintou Lyser certa vez a paisagem cujo fogo colorido refulgem o olhar e as faces das crianças debruçadas sobre os livros (BENJAMIN, 2009, p. 80).

Esse trecho de Walter Benjamin reflete o que pode ser a visão de um livro infantil: um espaço aberto ao encantamento, uma visão além, que as palavras ainda tentam desbravar, histórias que ficam mesmo depois de muitos anos e sempre voltam. A literatura infantil abarca diferentes e encantadoras formas de ver e pensar a própria literatura. 
Refletir sobre o livro, atentando "que o espaço da escrita é relativo, variável ou em expansão significa dizer que suas referências ou suas definições estão em movimento" (COMPAGNON, 1996, p. 106), implica considerar que esse movimento é essencial para a literatura e para análise da diversidade de livros destinados ao público infantil. Os livros assim o são, moventes dentro deles mesmos.

Beatrix Potter participou ativamente do processo de construção e publicação dos seus livros. Desde que os iniciava em forma de ilustrações, até o estágio de edição ao escolher o formato dos livros e as fontes das letras, com o fim de facilitar o processo de leitura pelas crianças, ela refletiu e lançou novos caminhos para se pensar o livro infantil.

\section{Referências}

BENJAMIN, Walter. Reflexões sobre a criança, o brinquedo e a educação. São Paulo: Editora 34, 2009.

BLANCHOT, Maurice. O livro por vir. Tradução Maria Regina Louro. Lisboa: Relógio D’Água, 1984. p. 235-255.

CALVINO, Italo. Sobre o conto de fadas. Lisboa: Teorema, 1996.

GOTLIB, Nádia. B. Teoria do conto. 6. ed. São Paulo: Editora Ática, 1991.

HUNT, Peter. Crítica, teoria e literatura infantil. Tradução Cid Knipel. São Paulo: Cosac Naify, 2010.

LINDEN, Sophie Van Der. Para ler o livro ilustrado. São Paulo: Cosac Naify, 2011.

MACHADO, Regina. Acordais: fundamentos teóricos poéticos da arte de contar histórias. São Paulo: DCL, 2004.

OLIVEIRA, Maria Angélica de. Caminhos da fábula: literatura, discurso e poder. Campina Grande, PB: Bagagem, 2011. 
POTTER, Beatrix. As aventuras de Pedro Coelho. Tradução Eduardo Bueno. São Paulo: Companhia das Letrinhas, 2014.

A história de Pedro Coelho. Tradução Leonardo Thierry. Rio de Janeiro: Lótus do Saber, 2009.

POWERS, Alan. Era uma vez uma capa. Tradução Otacílio Nunes. São Paulo: Cosac Naify, 2008.

TOLKIEN, J. R. R. Árvore e folha. Tradução Ronald Eduard Kyrmse. São Paulo: Editora WMF Martins Fontes, 2013.

Recebido em 6 de março de 2019.

Aceite em 15 de maio de 2019. 